\title{
Profitability on Albanian Supplementary Social Insurance Scheme: "Academic Titles" Case
}

\author{
Gentiana Sharku \\ ${ }^{1}$ Department of Finance, Faculty of Economy, University of Tirana, Albania \\ Correspondence: Gentiana Sharku, Department of Finance, Faculty of Economy, University of Tirana, Albania. \\ E-mail: gentasharku@yahoo.com
}

Received: February 8, 2017

Accepted: February 14, 2017

Online Published: February 17, 2017

doi:10.5539/ibr.v10n3p215

URL: https://doi.org/10.5539/ibr.v10n3p215

\begin{abstract}
The social insurance system in Albania is composed of three basic schemes: (i) mandatory scheme functioning on the "pay as you go" basis, (ii) voluntary scheme, protecting individuals who for specific reasons are not involved in the mandatory plan, and (iii) supplementary scheme, covering a specific category of individuals, who perform certain state functions and/or have academic titles. Regardless the classification, the supplementary scheme is a mandatory one. During 2015, Albanian government has revised the contribution rates for the supplementary scheme, as the scheme is suffering a deficit. The aim of this paper is to calculate the average rate of return on the contributions invested in this scheme, referring to the category of individuals having the "Professor" title. The calculations will be based on some actuarial assumptions. The data used in this paper will be of secondary type, based on the official statistics published by respective institutions.
\end{abstract}

Keywords: social insurance, contribution, rate of return

\section{Introduction}

The Supplementary state pension plan scheme has started to work since 1996. The Law no. 8097, dated 21.03.1996 "On supplementary state pension for the individuals with state and constitutional functions" ensured with special treatment a special category of individuals, who were performing certain state functions. The supplementary state pension for the professors and academics has been established by the Law no. 10 139, dated 15.05.2009, "On supplementary stated pension for the workers of universities, high schools, Albanology Studding Center, Science Academy and all other public researching Institutions in the Republic of Albania, holding science titles". The aim of this law was to provide the professor category with additional incomes during their retirement period. In 2015, the Albanian Parliament approved the Law no. 108/2015 with some additions and changes to the Law no. 10139 . One of the most important changes was the increase of the contribution rate from $3.5 \%$ to $5 \%$ for the Professors working in public institutions. As the contributions in the supplementary scheme have been considered as an investment for the retirement period, the aim of this paper is to calculate the rate of return earned in this retirement plan and to point out the impact of such changes in the law. The paper is focused only on the workers of public universities. The second section presents a short overview of the law regarding the supplementary insurance scheme and some statistics reported from respective official authorities. After a short literature review, methodology and the data set are described in the third section of the paper. The fourth section contains the results from the calculations based on four scenarios. Conclusions have been presented in the last section.

\section{Supplementary Insurance Scheme in Albania}

The supplementary state pensions plan is managed from the Social Insurance Institute, toward a fee paid from the Council of Ministers. The supplementary state benefits are financed from the state budget and the supplementary contributions.

In order to benefit the supplementary state pension, the professors have to fulfill the criteria for receiving the retirement pension based on the Law No. 7703 "On social insurance in the Republic of Albania". Therefore all the retired persons, who hold an academic title, have the right to require, under their own request, the supplementary benefits. They have to submit the required documents to the local agencies of the Social Insurance Institute. 
According to the Law no. 10139 , the supplementary pension is calculated as 1.3 percent of the referring salary for each annual period of exercising the "Professor" title, and 1.1 percent of referring salary for each annual period of exercising the "Professor Assistant" title. The law has defined the maximum value and the minimum value of the retirement pension. The Law no. 10139 has made a distinction between professor working in public institutions and the professors working in non-public institutions. The contribution rate for the workers of public institutions was 3.5 percent of the monthly gross salary. While the contribution rate for the workers in non-public institutions was 7 percent.

Actually the supplementary state pension scheme is running a deficit, as the overall social insurance scheme. At the end of 2015, the benefits paid to the individuals of "Professor" category were 109 million ALL, of which 73 million were financed from state budget. This means that only 30 percent of total benefits were financed from contributions. The number of beneficiaries has been continuously increased as the Table 1 shows.

Table 1. Beneficiaries number of the "Professor" category

\begin{tabular}{lcccc}
\hline Year & 2012 & 2013 & 2014 & 2015 \\
\hline Beneficiaries number & 29.448 & 31.175 & 31.478 & 31.867 \\
\hline
\end{tabular}

Source: Social Insurance Institute

In the frame of the social insurance reforms undertaken by the government, the law no. 10139 has been changed by the Law no. 108/2015. There were several changes regarding the maximum and minimum values of benefits and the procedures to be executed. But the most important change has been the increase of the contribution rate from $3,5 \%$ to $5 \%$ for professors working in public sector, without changing the benefit rate. The aim of the reforms was to improve the financial state of the social insurance system, by reducing the budget financing and enforcing the contributive principle on which the social insurance scheme is based.

\section{Literature Review}

There are various supplementary social insurance schemes all over the world. As the economic development of the countries is different, their social insurance schemes are different. Although in the most part of the world, the social insurance system is based on the "pay as you go" model. Regarding the supplementary scheme, they vary across the countries. There are few studies that quantify the extent of redistribution in collective funded pension schemes and calculate the rate of return on these schemes. The most part of the studies are focused on the determinants of pension coverage and pension scheme participation. Holzmann et al. (1999) by using e regression analysis found that individuals with low incomes, low education levels and self-employed are less likely to contribute to pension plans. Barrientos (1998a) found that age, employment history, firm size, occupational indicators, income levels and location are all significant in determining the probability of an individual participating in a pension plan. Bonenkampa (2007) has investigated the distribution in the second pillar of the Dutch pension system were the collective pension schemes in the second pillar are supplementary to the basic first-pillar pension provision and are characterized by funding, mandatory participation, forced annuitization and uniform pricing. Regarding the profitability of supplementary retirement schemes there are very few studies. Lüthen (2014) has examined the evolution of the profitability of Dutch pension contributions against the background of the reform for cohorts $1935-1945$. He measured the profitability with the internal rate of return (IRR) and concluded that for men the IRR declines from $2.4 \%$ to $1.2 \%$ and for women from $5.2 \%$ to $3.7 \%$. Internal rate of returns is used as an indicator of the profitability in this article.

There is no previous study regarding the profitability provided by the supplementary social insurance scheme in Albania. No rate of return has been calculated. Therefore, as the supplementary social contributions are considered as an investment for the future of a special category of people, the results from the calculations will be compared with the potential investment alternatives in Albania.

\section{Research Methodology and Data Set}

In order to measure the profitability of the supplementary social insurance plan, this paper uses one of the methods of capital budgeting, called the internal rate of return. It determines the rate of return which equates the present value of the cash inflows and the present value of the cash outflows of the investment. This particular rate of return is called the internal rate of return because it is a rate that is unique (internal) to that investment. In effect, the internal rate of return method sets up the following equation:

\section{Present Cost $=$ Present value of the Cash Inflows}

In the contexts of the supplementary social insurance plan, the profitability of pension contributions may be measured with the internal rate of return - IRR. This method computes an interest rate paid on contributions, which is sufficient enough to pay out the stream of pensions received by an individual. The method assigns an 
interest rate to contributions and pensions equating both sides of net present values. Here it yields an interest rate $i$, that equalizes the future value of contributions $C$ and the present value of the excepted value of pensions $P$ in the year of retirement $R$.

$$
\sum_{t=0}^{R-1} C \times(1+i)^{t}=\sum_{t=R}^{L} P \times 1 /(1+i)^{t}
$$

The left hand of Equation contains the future value of contributions from the year (0) the individual starts the contributions (C) until the retirement year R. The right-hand side of equation depicts the present value of the pensions $(\mathrm{P})$ from $\mathrm{R}$ until the year the individual is expecting to live $(\mathrm{L})$.

The model assumes that the following factors affect the internal rate of return:

\section{Life expectancy}

Individuals today live longer that any time in history. The life expectancy has been continuously increased: in 2005 it has been 77,3 years $(72,1)$ for women (men), while after ten years, in 2015, the life expectancy has been 79,7 years $(76,1)$ for women (men). The calculations in the paper, consider on average a life expectancy of 80 years old, taking in consideration the life quality of the individuals of "Professor" category and making no sex distinction.

\section{Retirement age}

When Germany, under Chancellor Otto von Bismarck, established the first formal retirement plan in 1880, age 65 was set as the national retirement age. With a life expectancy of 45 years at that time, very few Germans actually lived long enough to collect anything. It is perhaps surprising that more than a century later, age 65 remains synonymous with retirement. At the beginning of the twentieth century in the United States, life expectancy was about 50 years, with people typically worked until they died, with few living long enough to retire. As a consequence, the notion of "retirement" was foreign to most citizens (Skipper, 2000).

During last years as part of the retirement reforms undertaken by the Albanian government, the retirement age is increased and it is going to increase in the future. The calculations in the paper consider a retirement age of 68 years old, according to the Law "On high education".

\section{Contributions amount}

The contributions in the supplementary social insurance plan depend on the contributor's salary and the contribution rate determined by the law.

\section{Contribution timing}

The model considers the beginning of contribution at age 38 years old - fifteen years after finishing the graduated studies. According to the law, the doctorial studies last five years and the "Professor Assistant" title can be provided at least after five years after receiving the "Doctor" grade. Also, after 15 years of work, there are no more salary supplements and the salary remains constant at any age in the future. The model assumes that the "Professor" title is received five years after receiving the "Professor Assistant" title - the minimum period of time required by the Law "On high education".

\section{Benefits amount}

The benefits amount from the supplementary social insurance plan depends on the salary received as "Professor Assistant" and "Professor", their respective years, and the benefit rate determined by the Law.

\section{Benefits timing}

Benefits timing is determined by two first assumptions. As the Professor is intended to retire at 68 years old, and it is foreseen to live on average until 80 years old, the benefits are calculated to be received for a time period of 12 years.

\section{Accumulation period}

Contributions amounts and benefits amounts are both monthly paid/received. For calculations purpose, they are converted in annual amounts and accumulation period is considered to be one year.

\section{Results}

Based on the assumptions made in Section 3, the internal rate of return on supplementary social insurance plan is calculated hypothesizing four scenarios, as follows:

\subsection{First Scenario}

The calculation of internal rate of return is based on the present provisions of the Law no. 10139 taking into 
consideration the new contribution rate of $5 \%$. The calculations are performed based on the following assumptions:

The age of benefiting the "Professor Assistant" title is 38 years old, i.e. the individual will start the contributions in the supplementary plan at this age.

The age of benefiting the "Professor" title is 43 years old, i.e. the individual will start the contributions in the supplementary plan at this age.

The individual is retiring at 68 years old.

The individual is expected to live until 80 years old.

The actual gross salary of "Professor Assistant" is 101.050 ALL and is going to be constant. The annual contributions from 38 years old until 43 years old are calculated as follows:

$$
\text { 101.050 ALL } \times 0,05 \times 12=60.630 \text { ALL }
$$

The actual gross salary of "Professor" is 116.050 ALL and is assumed to be constant in the future. The annual contributions from 43 years old until 68 years old are calculated as follows:

$$
\text { 116.100 ALL } \times 0,05 \times 12=69.660 \mathrm{ALL}
$$

The annual benefits from 68 years old to 80 years old are calculated as follows:

$$
\text { 101.050 ALL } \times 0,011 \times 5 \times 12+116.100 \text { ALL } \times 0,013 \times 25=519.483 \mathrm{ALL}
$$

The Figure 1 shows the estimated cash flow.

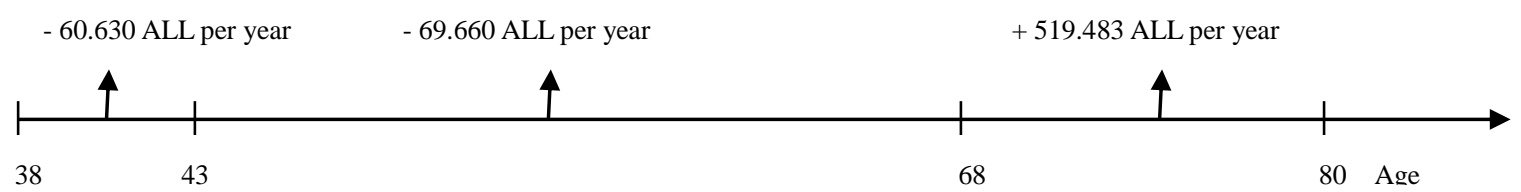

Figure 1. Estimated cash flow

The internal rate of return applied to the cash flow shown in the Figure 1 is calculated to be $5,14 \%$. Today, it's seemed to be a good rate of return from an investment, taking into consideration that the interest rates of safe investments have been fallen down to $1,33 \%$ (Treasury bills), while the rate of return on risky investments, such as Investments Funds is around 5,5\%.

\subsection{Second Scenario}

Analysis The calculation of internal rate of return is based on the provisions of the Law no. 10 139, before the changes of 2015, taking into consideration the contribution rate of $3.5 \%$. The assumptions regarding the contributions timing, the benefits timing, the benefits amounts are the same, except the contribution amounts that are calculated as follows:

The annual contributions from 38 years old until 43 years old are calculated as follows:

$$
\text { 101.050 ALL } \times 0,035 \times 12=42.441 \mathrm{ALL}
$$

The annual contributions from 43 years old until 68 years old are calculated as follows:

$$
\text { 116.100 ALL } \times 0,035 \times 12=48.762 \mathrm{ALL}
$$

The Figure 2 shows the estimated cash flow.

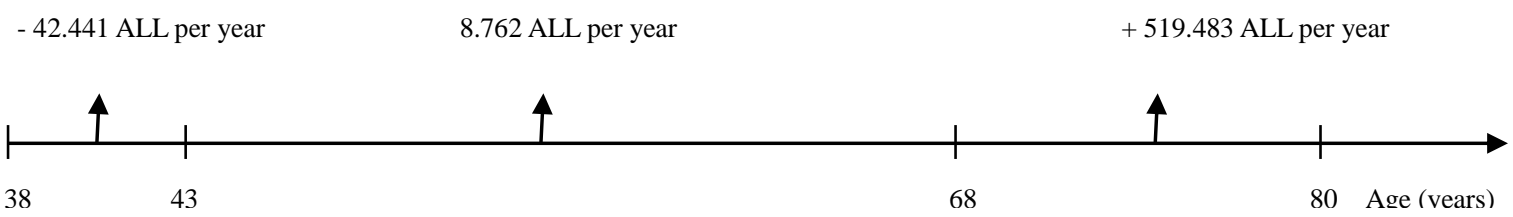

Figure 2. Estimated cash flow

The internal rate of return applied to the cash flow shown in the Figure 2 is calculated to be $6,71 \%$. The increase of the contribution rate from $3,5 \%$ to $5 \%$ has decreased the internal rate from supplementary insurance plan from $6,71 \%$ to $5,12 \%$. 


\subsection{Third Scenario}

This scenario takes in consideration the possibility of indexing the salary with the inflation rate. As result, the contribution and the benefits amounts will be changed (increased) as result of indexing both of them with the actual salary. The calculations regarding the timing of benefits and contributions remain the same, but the amounts of contributions and benefits are going to change year by year. If we assume an inflation rate of $1 \%$, the salary of "Professor Assistant" will increase from 101.050 ALL to 151.954 ALL after 42 years and the salary of "Professor" will increase from 116.100 ALL to 174.586 ALL after 42 years. The first annual contribution amount will be 60.630 ALL, but the last annual contribution amount will be 92.962 ALL. While the first annual benefit amount will be 700.185 ALL (at age 69) and the last benefit amount will be 781.174 ALL (at age 80).

The internal rate of return calculated according to the above mention assumptions, resulted to be $6.19 \%$. If the inflation rate will be considered higher, the rate of return will be even higher.

\subsection{Fourth Scenario}

As mentioned in the Section 1, the Law no. 10 139, "On supplementary stated pension for the workers of universities, high schools, Albanology Studding Center, Science Academy and all other public researching Institutions in the Republic of Albania, holding science titles" has been approved in 2009 and the calculations of the contributions have started since 2010. Therefore the major part of the present professors in public universities have a shorter period of contributions. This scenario takes into consideration the professors with a present age of 50 years old and 60 years old. Considering the fact that the salary during last six years have been little changed or has not changed at all, the calculations assume a constant salary of 116.100 ALL. Regarding the contributions amount, for the first six years they are calculated based on a rate of 3,5\% and for the remaining period they are calculated based on a rate of 5\%. Also the calculations assume that the contributions are made under the status of "Professor" title.

Figure 3 shows the estimated contributions and benefits regarding the 50-years-old Professor in 2016.

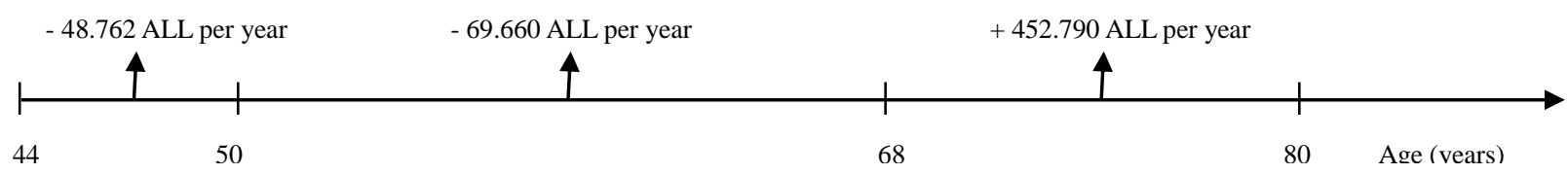

Figure 3. Estimated cash flow for the 50-years-old professor

The internal rate of return applied to the cash flow shown in the Figure 3 is calculated to be $6,62 \%$.

Figure 4 shows the estimated contributions and benefits regarding the 60-years-old Professor in 2016.

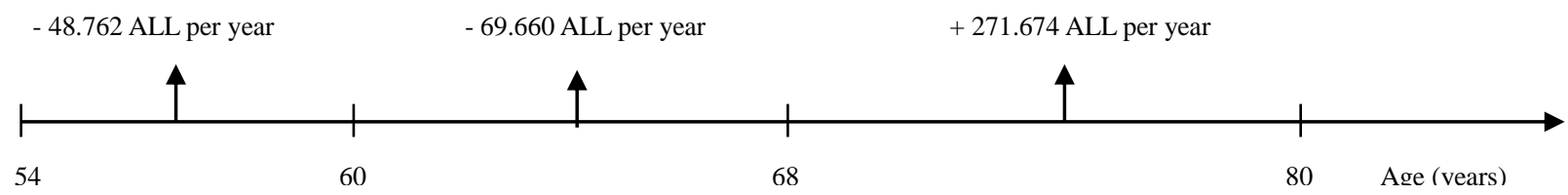

Figure 4. Estimated cash flow for the 60-years-old professor

The internal rate of return applied to the cash flow shown in the Figure 4 is calculated to be $10,08 \%$. Due to the shorter period of contributions, the rate of return on the supplementary insurance plan is the highest among the assumed scenarios.

\section{Discussion}

The supplementary insurance scheme is running in deficit, as the other schemes of the social insurance system. The governments have undertaken several reforms to release the state bur-den. In the end of 2015, Law no. 10 139, "On supplementary stated pension for the workers of universities" was changed by increasing the contribution rate from $3,5 \%$ to $5 \%$. With no doubt, due to the contributions' rate increase, the profitability on this plan has been de-creased. According to the calculations performed in this paper, the rate of return is supposed to be decreased from $6,71 \%$ to $5,14 \%$. In nowadays, when the interest rates are continually falling down, $5,14 \%$ is still considered as a high rate. But there is a concern about the possible future interventions in the law. The aim of the Law no. 10139 is to reward the individuals of "Professor" category, with some additional incomes during 
retirement. "Is it still the aim?" or "Is it going to be used as a mean to pay out the social insurance budget deficit?" If the second question is true, than firstly the purpose of the Law has to change.

\section{References}

Barrientos, A., (1998a). Pension Reform, Personal Pensions and Gender Differences in Pension Coverage. World Development, 26(1), 125-137. https://doi.org/10.1016/S0305-750X(97)10009-2

Black, K., \& Skipper, H. (2000). Life and health insurance. Prentice Hall.

Bonenkamp, J. (2007). Measuring lifetime distribution in Ditch occupational pensions. CPB Discission paper, 81 .

Boskin, M. J. (1977). Social Security and Retirement Decisions. Economic Inquiry, 15(1), 1-25. https://doi.org/10.1111/j.1465-7295.1977.tb00446.x

Boskin, M. J., \& Hurd, M. D. (1978). The Effect of Social Security on Early Retirement. Journal of Public Economics, 10(3), 361-377. https://doi.org/10.1016/0047-2727(78)90052-X

Freiden, A., Dean, L., \& Ronald, H. (1976). Internal Rates of Return to Retired Worker-Only Beneficiaries under Social Security, 1967-1970. Studies in Income Distribution, 5, U. S. Department of Health, Education, and Welfare.

Government of Republic of Albania. (2009). On supplementary stated pension for the workers of universities, high schools, Albania Studding Center, Science Academy and all other public researching Institutions in the Republic of Albania, holding science titles. Law No. 10139.

Government of Republic of Albania. (2015). On some extensions and changes of the law no. 10139, Law no. $108 / 2015$.

Government of Republic of Albania. (1993). On social insurance in Republic of Albania, Law No. 7703.

Government of Republic of Albania. (2015). On high education and science research in high education institutions in the Republic of Albania, Law No. 80/2015.

Government of Republic of Albania. (1996). On supplementary state pension for the individuals with state and constitutional functions, Law No. 8097.

Holzmann, J. (1999). Social protection as social risk management: conceptual underpinnings for the social protection sector strategy paper.

Leimer, D. R. (1978). Projected Rates of Return to Future Social Security Retirees Under Alternative Benefit Structures. In U. S. Department of Health, Education, and Welfare, Policy Analysis with Social Security Research Files, 235-268.

Luthen, H. (2014). Rates of return and early retirement disincentives: evidence from a German pension reform. Discussion paper. https://doi.org/10.2139/ssrn.2456128

Official webpage of National Statistical Institute of Albania: www.instat.gov.al

Official webpage of Social Insurance Institute of Albania: www.issh.gov.al

\section{Copyrights}

Copyright for this article is retained by the author(s), with first publication rights granted to the journal.

This is an open-access article distributed under the terms and conditions of the Creative Commons Attribution license (http://creativecommons.org/licenses/by/4.0/). 